\title{
A Case of Cefixime, Ofloxacin Combination Tablet Induced Erythematous Macules
}

\author{
Prashant Dass $^{1, *}$, Michell Michell Gulabani $^{2}$, Shrinivas Raikar ${ }^{3}$ \\ ${ }^{1}$ Department of Pharmacology, M.R. Medical College, Gulbarga, India \\ ${ }^{2}$ Department of Anesthesia and Critical Care, Dr. Ram Manohar Lohia Hospital, New Delhi, India \\ ${ }^{3}$ Department of Pharmacology, Kamineni Institute of Medical Sciences, Narketpally, India
}

\begin{abstract}
Erythematous macule is a type of rash which is associated with many dermatological conditions. We present a case of erythematous macules induced by administration of cefixime + ofloxacin tablet, its treatment and management. A seventeen year old female patient reported to us with a presentation of rash with scaling and itching for three days. On administration of the drug, the patient described a sensation of itching and discomfort on her entire body. The duty doctor attended the patient and immediately stopped the further administration of the offending medication. The patient was infused intravenous (iv) Dexamethasone $4 \mathrm{mg} / \mathrm{ml}$ and iv Pheniramine Maleate 1 ampoule $(25 \mathrm{mg}$ in $2 \mathrm{ml}$ ) immediately. The patient reported back in for follow-up and was without any residual rashes or other such complaints. She was advised to remember and refrain from the use of drugs in the offending class.
\end{abstract}

Key words: Allergy, Cefixime, Erythema, Fever, Ofloxacin, Macule.

Key Messages: Erythematous macules induced by drugs should be thoroughly investigated. The offending drug should be stopped and appropriate treatment should be provided at the earliest.

\section{INTRODUCTION}

Erythematous macule is a type of rash which is associated with many dermatological conditions. Some common ailments representative of erythematous macules include varied pathological processes such as Erythema Multiforme, Viral Exanthema, Drug Reaction and Insect-bite Reaction. ${ }^{1}$

A macular, often 'Morbillic-form' rash is encountered initially. The individual lesion may often show a dark, dusky centre reminiscent of target lesion. Usually they are flat, tender and exhibit a positive Nikolsky sign. ${ }^{2}$ Over the course of time, some lesions might become flaccid and occasionally hemorrhagic blisters.

The lesion is shown to rapidly increase in size and number and reaches maximal disease expression within four-five days. ${ }^{3}$ The common sites for erythematous macules are face, neck, chest and limbs. ${ }^{4}$

\section{Case History}

We present a case of erythematous macules induced by administration of Cefixime + Ofloxacin tablet, its treatment and management. A seventeen year old female patient reported to Basaveshwar Teaching and General Hospital on $6^{\text {th }}$ May 2014 with a presentation of rash with scaling and itching for three days.

The patient reported that she previously had a bout of fever with cough and expectoration for which she was prescribed a fixed-dose combination tablet of Cefixime $200 \mathrm{mg}$ and Ofloxacin $200 \mathrm{mg}$ by a local Physician. The Physician prescribed this drug to be taken twice-daily for a duration of five days.
DOI: $10.5530 /$ ijopp.7.4.10

Address for correspondence: Dr. Prashant Dass, Department of Pharmacology, M.R. Medical College, Gulbarga, Karnataka585105, India

Phoneno:00918095754155 prashantdass@ymail.com

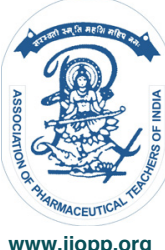


The patient reportedly took the initial dose without any side-effect. However, on administration of the second dose, the patient immediately described a sensation of itching and discomfort on her entire body. Shortly in a span of three-four hours, her entire body was covered in red coloured rashes exhibiting scaling. She reported to our Hospital after two days where she was thoroughly examined.

During the consultation her vitals were near normal; Pulse Rate- 84 bpm, Blood Pressure- 110/80 mmHg, Temperature (Axillary) - $37.4^{\circ} \mathrm{C}$. Chest auscultation revealed slight wheezing; abdominal palpation and central nervous system evaluation were within normal limits. History elucidation from the patient revealed an absence of allergic-diathesis as such.

The Dermatologist on duty attended the patient and immediately stopped the further administration of the offending medication. The patient was infused intravenous iv dexamethasone $4 \mathrm{mg} / \mathrm{ml}$ and iv pheniramine maleate 1 ampoule $(25 \mathrm{mg}$ in $2 \mathrm{ml}$ ) immediately. After the administration of these drugs the patient felt relieved of her symptoms almost immediately and requested to be discharged. After further observation for two hours, the patient was discharged in the custody of her guardians. She was prescribed to take oral prednisolone tablets $40 \mathrm{mg} /$ day for 1 week, then $30 \mathrm{mg} /$ day for next week, then $20 \mathrm{mg} /$ day for next week, then $10 \mathrm{mg} /$ day for next week, then alternate day $10 \mathrm{mg} /$ day for one week, then alternate $5 \mathrm{mg}$ /day for one week and then to stop altogether. She was hitherto advised to come for follow-up after cessation of this schedule lest any other problems arose.

The patient reported back in out-patient department for follow-up on $21^{\text {st June }} 2014$ and was without any residual rashes or other such complaints. She was advised to remember and refrain from the use of drugs in the offending class.

\section{DISCUSSION}

Erythematous macules can be caused by a variety of pathological processes and drug-administration is one of the important causes. ${ }^{5}$

Cefixime is a $3^{\text {rd }}$ generation Cephalosporin. It can be administered orally at a dose of 200 or $400 \mathrm{mg} /$ day. ${ }^{6}$ Being a cephalosporin, its mechanism of action involves disruption of the peptidoglycan layer of bacterial cell wall. Third generation cephalosporins have expanded coverage against many gram negative and gram positive micro-organisms. Currently, $3^{\text {rd }}$ generation cephalospo- rins like cefixime, are used to treat a wide variety of serious infections which are resistant to other commonly employed anti-microbial drugs. However, their use should be avoided in case of enterobacter infections. ${ }^{7}$

Cefixime as other cephalosporins, can elicit a variety of hypersensitivity reactions that are identical to those of penicillins. Common adverse events associated with cefixime include fever, skin rashes, anaphylaxis, granulocytopenia, haemolytic anemia etc. ${ }^{8}$

Ofloxacin is a $2^{\text {nd }}$ generation fluoroquinolone and is a racemic mixture of 50\% Levofloxacin and 50\% dextrofloxacin. ${ }^{9}$ Fluoroquinolones block bacterial DNA synthesis by inhibiting bacterial topoisomerase II (DNA Gyrase) and Topoisomerase IV. It has a half-life $\left(t_{1 / 2}\right)$ of 5-7 hours with an oral bioavailability up to $95 \%$. Ofloxacin is administered for both gram negative and gram positive bacteria and is administered in a dose of 400 mg once a day.

Fluoroquinolones are effective in the treatment of urinary tract infection, bacterial diarrhoea and respiratory tract infection and are frequently employed for the same. Ofloxacin is one drug which is usually well tolerated and is devoid of serious adverse reactions. However, in 2004 the US-FDA requested new warning label to be added to all the fluoroquinolones regarding peripheral neuropathy, tendon damage, QT ${ }_{c}$ prolongation, StevenJohnson syndrome and epidermal necrolysis. ${ }^{10}$

Our patient was administered a fixed-dose combination of cefixime $200 \mathrm{mg}$ and ofloxacin $200 \mathrm{mg}$ for alleviation of her symptoms of fever with expectoration and cough by a local physician. This particular drug is a favourite of physicians these days as it provides a multi-pronged therapeutic approach to many infectious causes and has a relatively safe profile.

The erythematous macular rash which occurred in our patient can be attributed as a rare side effect of any of these two co-administered drugs. As it was a fixed-dose combination tablet and both the drugs have almost similar pharmacokinetics, one cannot clearly implicate which drug was the offending medication. However, in order to prevent future episodes of such dermatological pathologies, our patient has been advised to refrain from the use of fluoroquinolones, cephalosporins and penicillins. The patient was advised to retain this information and to provide the same to any physician hitherto treating her.

The major challenge which this case presented was the prompt identification of the offending agent as well as the holistic management of the symptoms exhibited by the patient. 


\section{REFERENCES}

1. Freedberg IM, Eisen AZ, Wolff K, et al. Fitzpatrick's Dermatology in General Medicine $6^{\text {th }}$ Edition Chapter 2003; 58: 550-1.

2. Salopek TG. Nikolsky's sign: is it 'dry'or is it 'wet'? British Journal of Dermatology 1997; 136(5): 762-7.

3. Clark HJ, Weston WL, Tonnesen MG. Erythema multiforme: a critical review of characteristics, diagnostic criteria, and causes. Journal of the American Academy of Dermatology 1983; 8(6): 763-75.

4. Bannister MJ, Rubel DM, Kossard S. Mid-dermal elastophagocytosis presenting as a persistent reticulate erythema. Australasian Journal of dermatology 2001; 42(1): 50-4.

5. Roujeau JC. Clinical heterogeneity of drug hypersensitivity. Toxicology 2005; 209(2): 123-9.

6. Carruthers S, Hoffman G, Brian B. Drug Therapy of Common Diseases: Problem-Based Therapeutic Decisions. Melmon and Morreli's Clinical Pharmacology 4th Edition Chapter 2000; 14: 901-3.
7. Neu HC. In vitro activity of a new broad spectrum, beta-lactamase-stable oral cephalosporin, cefixime. The Pediatric infectious disease Journal 1987; 6(10): 958-62.

8. Brunton LL, Chabner BA, Knollmann BC. Penicillins, Cephalosporins and Other $\beta$-Lactam Antibiotics. Goodman \& Gilman's The Pharmacological Basis of Therapeutics $12^{\text {th }}$ Edition Section VII Infectious Diseases: Chapter 53- Online Edition; 2011.

9. Boopathy D, Prakash M, Mathew B. Method development and validation of simultaneous determination of Ofloxacin and Satranidazole in pharmaceutical dosage form by RP-HPLC. Der Pharmacia Letter 2010; 2(2): 22(6).

10. Tanne JH. FDA adds "black box" warning label to fluoroquinolone antibiotics. BMJ. 2008; 337(7662): 135. 